\title{
APLICAÇÃO DE MARCADORES SCARS PARA SELEÇÃO DE LINHAGENS RESISTENTES À ANTRACNOSE EM FEIJOEIRO $\left({ }^{1}\right)$
}

\author{
ANA LUIZA AHERN BERALDO $\left({ }^{2}\right)$; CARLOS AUGUSTO COLOMBO $\left({ }^{3}\right)$; ALISSON FERNANDO CHIORATO $\left({ }^{4}\right)$; \\ MARGARIDA FUMIKO ITO $\left({ }^{5,6}\right)$; SÉRGIO AUGUSTO MORAIS CARBONELL $\left({ }^{4,6 *}\right)$
}

\begin{abstract}
RESUMO
No Brasil, a produtividade do feijoeiro (Phaseolus vulgaris) é baixa, decorrente principalmente de doenças, como a antracnose, causada pelo patógeno Colletotrichum lindemuthianum Sacc \& Magnus. Já foram descritas no Brasil 50 raças fisiológicas do patógeno sendo as raças 31, 65 e 89 as mais importantes no Estado de São Paulo. No presente trabalho, seis marcadores do tipo SCAR (Sequence-Characterized Amplified Regions) foram avaliados em 42 genitores e 76 linhagens derivadas do Programa de Melhoramento do Instituto Agronômico - IAC. Os objetivos do trabalho foram: avaliar o potencial dos SCARs na identificação de genótipos contendo genes de resistência ao C. lindemuthianum e detectar os prováveis genes de maior freqüência nos genótipos avaliados. Com base nas avaliações, foram identificados três genitores e nove linhagens com quatro genes de resistência, sendo o gene Co-6 o mais freqüente, seguido por $\mathrm{Co}-4^{2}, \mathrm{Co}^{3} 3^{3}, \mathrm{Co}-5$, e Co-4.
\end{abstract}

Palavras-chave: Antracnose, Colletotrichum lindemuthianum, Phaseolus vulgaris, genes de resistência, feijão.

\section{ABSTRACT \\ USE OF SCAR MARKERS IN COMMON BEAN BREEDING FOR ANTHRACNOSE RESISTANCE}

Low yield of common bean, in Brazil, occurs mainly due to diseases such as anthracnose caused by Colletotrichum lindemuthianum Sacc \& Magnus. Fifty physiological strains of this fungus have already been described races 31, 65 and 89 being the most important in the State of São Paulo. In the present work, six SCAR (Sequence-Characterized Amplified Regions) markers were evaluated in 42 parental lines and in 76 lines of the bean breeding program of Instituto Agronômico (IAC) aiming at to identify genotypes carrying resistance genes to $C$. lindemuthianum and the probable most frequent genes. Based on the SCAR markers, three parents and nine derived lines were identified as carrying four resistance genes, demonstrating the effectiveness of the markers for the on going breeding program. Co-6 was the most frequent resistance gene followed by $\mathrm{Co}_{-} 4^{2}, \mathrm{Co}_{-} 3^{3}, \mathrm{Co}-5$, and $\mathrm{Co}-4$.

Key words: Anthracnose, Colletotrichum lindemuthianum, Phaseolus vulgaris, resistance genes, common beans.

$\left({ }^{1}\right)$ Recebido para publicação em 28 de agosto de 2007 e aceito em 24 de setembro de 2008.

( ${ }^{2}$ ) Instituto Agronômico (IAC), Pós-Graduação em Agricultura Tropical e Subtropical, Caixa Postal 28, 13001-970 Campinas (SP), Brasil.

$\left({ }^{3}\right)$ Centro de Pesquisa e Desenvolvimento de Recursos Genéticos Vegetais, Instituto Agronômico (IAC), Campinas (SP), Brasil.

$\left({ }^{4}\right)$ Centro de Análises e Pesquisa Tecnológica do Agronegócio dos Grãos e Fibras, Instituto Agronômico (IAC), Campinas (SP), Brasil. E-mail: carbonel@iac.sp.gov.br $\left(^{*}\right)$ Autor correspondente.

$\left({ }^{5}\right)$ Centro de Pesquisa e Desenvolvimento de Fitossanidade, Instituto Agronômico (IAC), Campinas (SP), Brasil.

$\left({ }^{6}\right)$ Bolsista CNPq. 


\section{INTRODUÇÃO}

O feijoeiro (Phaseolus vulgaris L.) é fonte importante de proteína, carboidratos, vitaminas e minerais da população brasileira. A média da produtividade da cultura é baixa quando consideramos o alto potencial genético das cultivares utilizadas atualmente. Uma das razões desta baixa produtividade é a ocorrência da antracnose, causada por C. lindemuthianum Sacc \& Magnus, responsável por perdas de até $100 \%$ em lavouras. Uma das dificuldades no controle da antracnose é a existência de grande número de raças do patógeno. No Brasil, já foram identificadas 50 raças fisiológicas (Thomazella et al., 2000; AlzateMarin e SARTorato, 2004; Rava et al., 1994; Balardin, 1997; CARbonell et al., 1999; MahuKu e Riascos, 2004; TAlamini et al., 2004). Em São Paulo, CARbonell et al., (1999) observaram que as raças fisiológicas 31, 65 e 89 são as mais frequentes, sendo a última a mais agressiva.

Até o momento foram descritos 10 genes associados à resistência à antracnose sendo eles: $\mathrm{Co}$ 1 (e os alelos $\mathrm{Co}_{0} 1^{2}, \mathrm{Co}_{-} 1^{3}, \mathrm{Co}_{-} 1^{4}$ e $\left.\mathrm{Co}_{-} 1^{5}\right), \mathrm{Co}-2$, o Co-3 (e os alelos $\mathrm{Co}_{0} 3^{2}$ e $\mathrm{Co}_{0} 3^{3}$ ), Co-4 (e seus alelos $\mathrm{Co}_{-} 4^{2}$ e Co- $\left.4^{3}\right), \mathrm{Co}-5, \mathrm{Co}-6, \mathrm{Co}-7, \mathrm{Co}-8, \mathrm{Co}-10$ e Co-11, sendo apenas $\mathrm{Co}-8$ recessivo (Bean Improvement Cooperative - BIC, 2008).

A piramidação desses genes em uma mesma cultivar é a estratégia mais usada pelos melhoristas (Castanheira et al., 1999). A seleção de plantas contendo diversos genes de resistência baseada apenas no fenótipo é difícil, uma vez que a ação de um gene pode mascarar a ação de outro. Nestes casos, os marcadores de DNA auxiliam na identificação de genes piramidados em uma mesma planta sem a necessidade de inoculação com o patógeno ou da realização do teste de progênie (HitTALMAni et al., 2000). Existem vários marcadores moleculares que podem ser utilizados no melhoramento genético de plantas, destacando-se os SCARs (SequenceCharacterized Amplified Regions), que são importantes por serem altamente específicos e de fácil uso (NiETSCHE et al., 2000).

Atualmente, existem 45 SCARs ligados a genes de resistência a diversas doenças do feijoeiro e, no caso da antracnose, já foram identificados os locos SCAreoli (Co-2), SQ4 (Co-2), SW12 (Co-3), SY20 (Co4), SC08 (Co-4), SAS13 (Co-42), SH18 (Co- $\left.4^{2}\right)$, SBB14 $\left(\mathrm{Co}_{-} 4^{2}\right), \mathrm{SAB} 3(\mathrm{Co}-5), \mathrm{SZ20}(\mathrm{Co}-6), \mathrm{SZ} 04(\mathrm{Co}-6), \mathrm{SB} 12$ $\left(\mathrm{Co}-3^{3}\right)$ e SF10 (Co-10) (BIC, 2008).

O uso de marcadores moleculares na seleção de plantas resistentes em populações segregantes é essencial na piramidação de genes de interesse. Resultados desta estratégia no melhoramento de plantas foram relatados por HUANG et al., 1997;
SANCheZ, 2000; Singh et al., 2001 em arroz, e por RAGAGNIN et al., 2003 e ARRUDA et al., 2005, em feijoeiro.

No final do programa de melhoramento, as linhagens melhoradas tendem a ser semelhantes fenotipicamente quanto aos caracteres de produtividade, resistência a doenças, tipo de grão e porte de plantas. Assim, os marcadores moleculares podem auxiliar o melhorista a selecionar, dentre as linhagens fenotípicamente semelhantes, aquelas que contenham o maior número de marcas associadas à resistência ou alguma outra marca específica de interesse.

Este trabalho teve como objetivo avaliar seis marcadores SCARs associados a genes de resistência à antracnose em 118 acessos de feijoeiro, sendo 42 genótipos utilizados como genitores pelo programa de melhoramento do IAC e 76 linhagens resultantes de suas recombinações, identificando genótipos que contenham o maior número de genes de resistência à antracnose. Além disso, relatar quais os genes estão presentes nestes acessos para sua utilização como genitores, na orientação de possíveis trabalhos de piramidação gênica.

\section{MATERIAL E MÉTODOS}

Foram avaliados 42 genitores do Programa de Melhoramento do IAC e as 76 linhagens de feijoeiro resultantes de suas recombinações genéticas através de cruzamentos múltiplos.

Foram utilizados isolados das raças fisiológicas 31, 65 e 89 de C. lindemuthianum. O isolamento do patógeno foi realizado de acordo com método proposto por FigueIREDO (1967). Oito sementes de cada acesso, além da cultivar suscetível (Rosinha $\mathrm{G}_{2}$ ) foram germinadas a $25{ }^{\circ} \mathrm{C}$, por três dias, em uma câmara de germinação e transplantadas para caixas com vermiculita esterilizada. Após cinco dias do transplante, as plântulas foram submetidas à inoculação com uma suspensão de $1,2 \times 10^{6}$ conídios $/ \mathrm{mL}$, em toda a superfície foliar. Sete a dez dias após a inoculação, as plântulas foram classificadas segundo método proposto pelo CIAT (1990), utilizando uma escala que varia de 1 a 9 - as plantas com notas de 1 a 3 são consideradas resistentes e com notas de 4 a 9 , suscetíveis.

A extração do DNA foi baseada no protocolo CTAB, adaptado por Hoisington et al. (1994). Após a extração, a qualidade e quantidade de DNA foram analisadas em eletroforese de gel de agarose a $1 \%$. Todos os materiais vegetais utilizados para extração do DNA foram coletados de plantas únicas, e mantidos em casa de vegetação para a produção de sementes. Estas sementes foram posteriormente utilizadas para a produção de plântulas e inoculação com as raças fisiológicas do patógeno. 


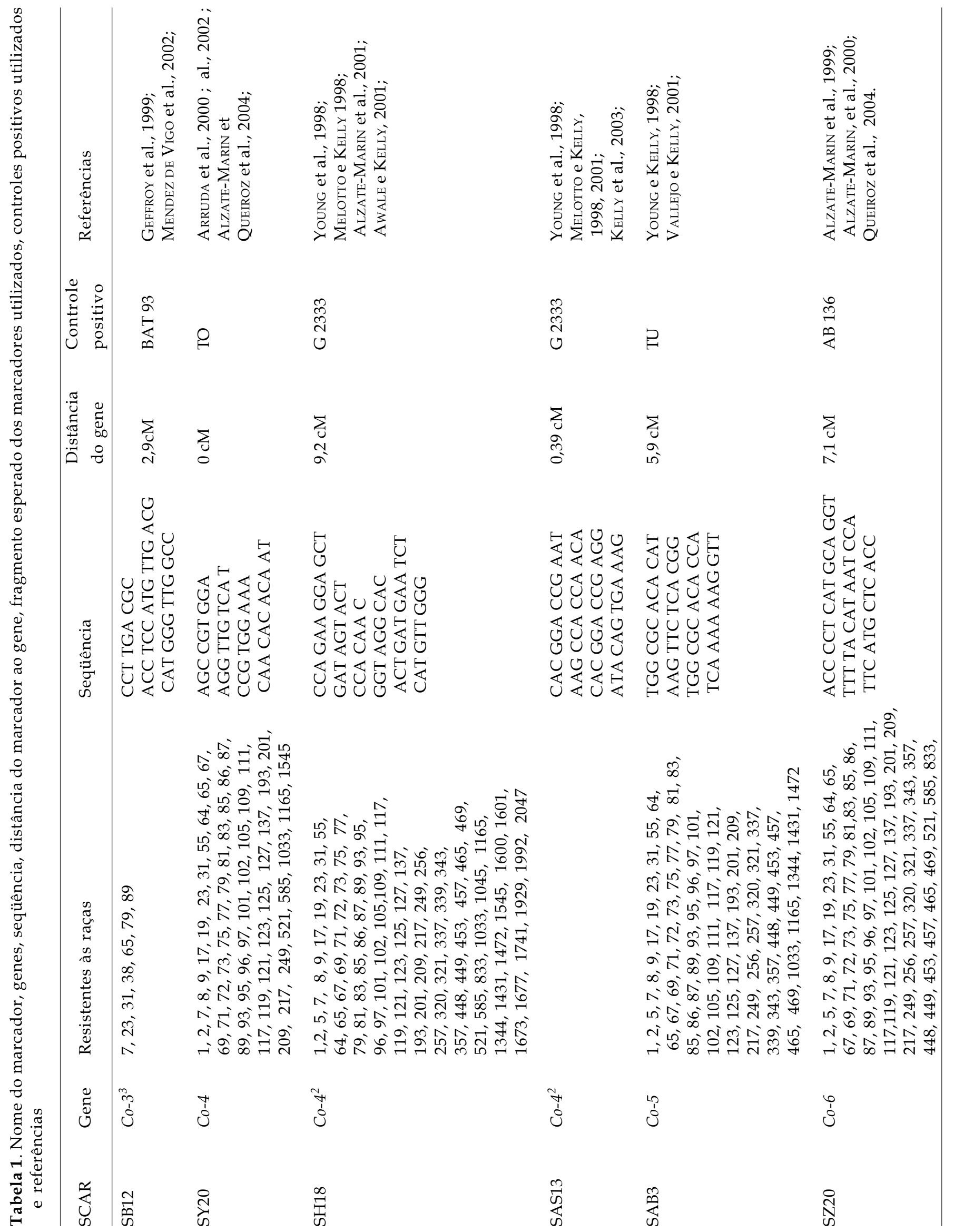


Visando confirmar a eficácia dos marcadores SCARs em detectar genótipos com possíveis genes de resistência, seis marcadores ligados aos mesmos foram utilizados (Tabela 1).

Para obtenção dos amplificados SCARs, inicialmente, foram testadas as condições experimentais descritas pelos autores (Tabela 1). Foi necessário, porém, estabelecer experimentalmente novas condições de reação, tanto para as temperaturas de anelamento como para as concentrações de cada componente da reação de PCR (Polimerase Chain Reaction). Para cada reação (25 iL), foram utilizados $75 \mathrm{ng}$ de DNA, 0,2 mM de dNTP, 2,0 $\mathrm{mM}$ de $\mathrm{MgCl}_{2}$, 1x Tampão de reação, $1 \mathrm{U}$ da enzima Taq DNA polymerase e 5 pmol da cada primer. A condição de reação estabelecida foi $94{ }^{\circ} \mathrm{C}$ por 3 minutos, seguidos de 30 ciclos de $94{ }^{\circ} \mathrm{C}$ por 1 minuto, $68{ }^{\circ} \mathrm{C}$ por 1 minuto e $72{ }^{\circ} \mathrm{C}$ por 1 minuto e 30 segundos, com uma extensão final a $72{ }^{\circ} \mathrm{C}$ por 7 minutos. O termociclador utilizado foi o PTC-100 (MJ Research, Inc).

O volume total da reação de PCR foi disposto em gel de agarose $2 \%$ para separação por eletroforese dos amplificados obtidos. Para visualização, o gel foi disposto em uma solução contendo brometo de etídeo por 10 minutos e, em seguida, visualizado sob luz ultravioleta. A imagem obtida dos géis foi digitalizada em fotodocumentador específico e as marcas SCARs interpretadas na forma de presença ou ausência (1 ou 0 respectivamente) para cada marca amplificada. A cada gene analisado nas linhagens avançadas, um genótipo controle portador do gene (resistente) e um não portador do gene (suscetível) foram adicionados para efeito de controle experimental da reação de PCR, assim como uma reação em branco (sem presença de DNA). Os tamanhos dos fragmentos amplificados foram estimados através de um marcador de peso molecular conhecido.

\section{RESULTADOS E DISCUSSÃO}

Os programas de melhoramento de feijoeiro geram centenas de novas linhagens por ano, oriundas de cruzamentos múltiplos entre diversos genitores com características agronômicas favoráveis, tipo resistência a doenças. Para isso, visam incorporar em uma única planta, o maior número de genes associados à resistência. Para tal, utilizam genitores provenientes dos dois centros de origem do feijoeiro o Mesoamericano e o Andino que, por meio da piramidação, promovem resistência mais ampla e duradoura.

Como forma de obtenção de linhagens resistentes às raças mais importantes da antracnose no Brasil, os genótipos mais utilizados nos blocos de cruzamentos são: G 2333 (Co-42, Co-5 e Co-7), PI $207262\left(\mathrm{Co}_{-} 4^{3}\right.$ e $\left.\mathrm{Co}-3^{3}\right)$, TO (Co-4), AB 136 (Co-6 e co$8)$ e TU (Co-5).

Avaliando os 42 genitores utilizados nos cruzamento dirigidos do IAC, através dos marcadores SCARs, pode-se observar que três acessos usados (G 2338, Pompadour, Vax 1) possuem ao menos quatro genes de resistência, e em outros dez genitores há ao menos três genes de resistência (Figura 1 e Tabela 2).

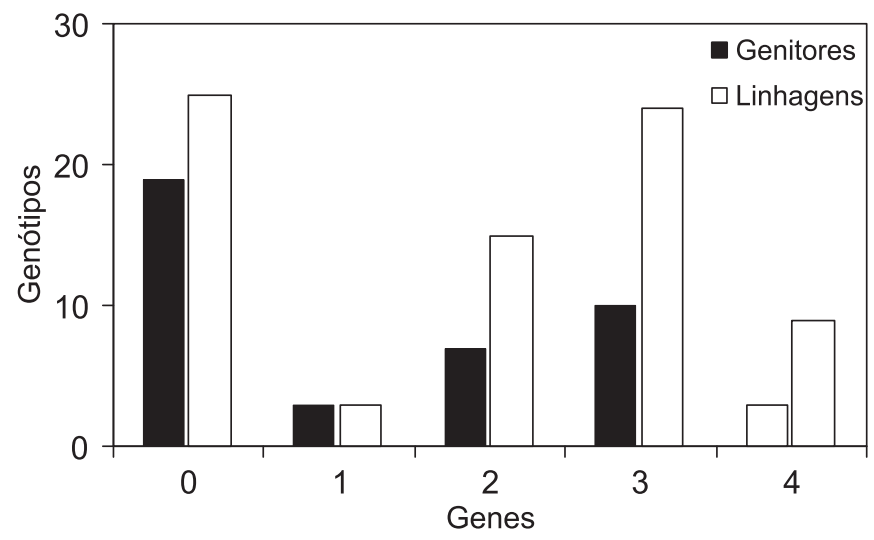

Figura 1. Número de genes de resistência à antracnose presentes em genitores e linhagens de feijoeiro estimados por marcadores moleculares SCARs.

Entre as 76 linhagens estudadas, em nove constaram quatro genes de resistência (Figura 1 e Tabela 2), com destaque para as linhagens Gen96A5P1-1, Gen99TG35-29, Gen99TG47-38-2 e Gen96A98-12-1-51-1 de grão carioca, Gen96A3-P4-11 de grão preto, Gen96A100-6-1-53-1 de grão rosinha, e as linhagens, Gen99TG36-9, Gen96A14-7-3-15-3V2 e Gen99TG50-47 de grãos mulatinho, vermelho e rajado respectivamente.

Além de demonstrar sua utilidade na identificação de genótipos contendo genes de resistência piramidados nos genótipos, os marcadores SCARs podem ser utilizados também na seleção de materiais promissores uma vez que revelaram a superioridade de linhagens que já haviam sido previamente selecionadas pelo programa, com base em qualidade agronômica e resistência às raças 31,65 e 89 do patógeno da antracnose como as linhagens Gen99TG50-47 e Gen96A100-6-1-53-1 e que se tornaram cultivares IAC (IAC-Harmonia e IAC-Galante).

Além de auxiliar na indicação e seleção de novas linhagens, o marcador também foi útil ao demonstrar a importância de algumas linhagens como a Gen96A98-12-1-51-1 que revelou quatro marcas associadas à resistência. 


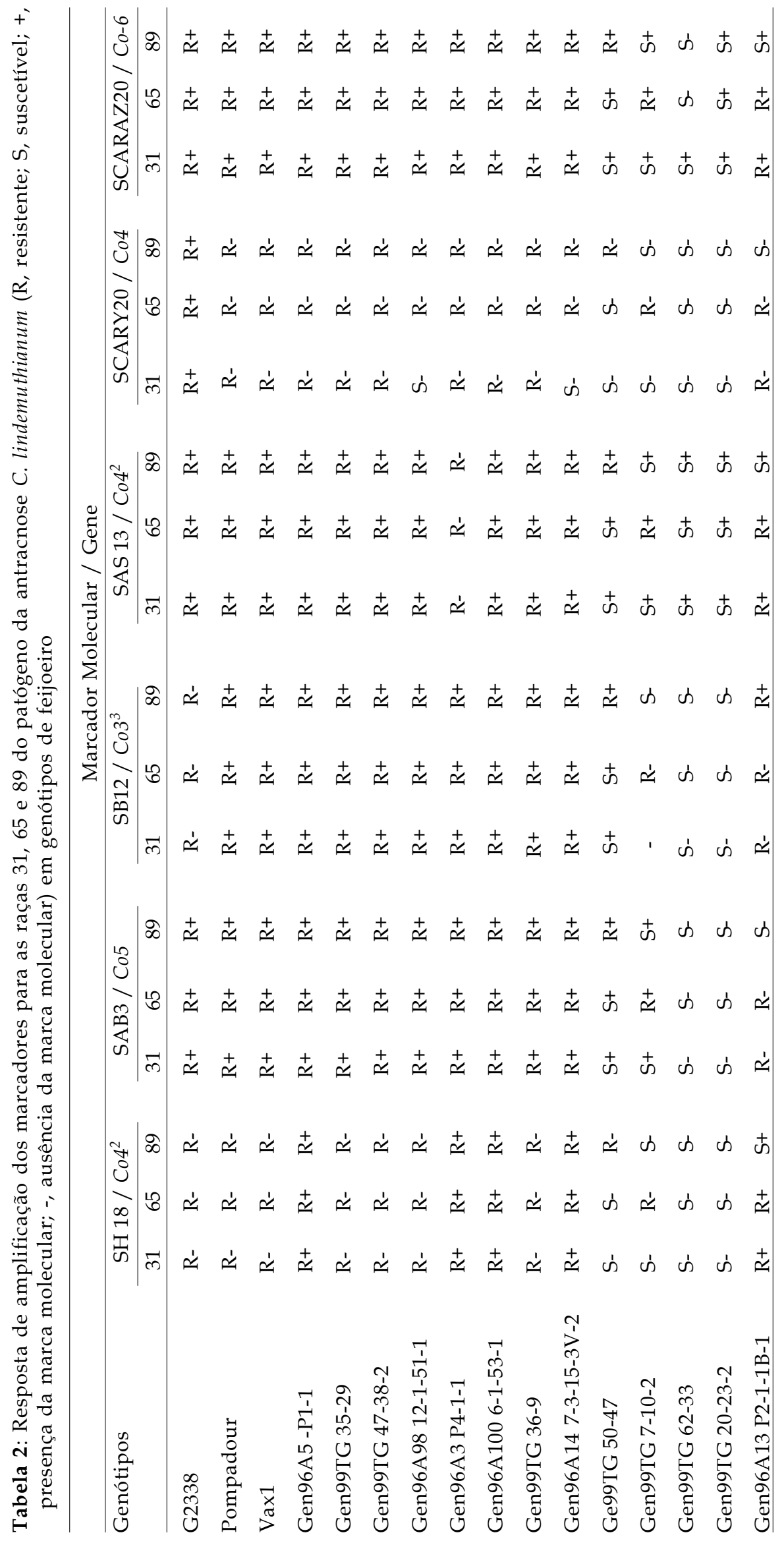


Essa linhagem é de excelente qualidade de grãos tipo carioca, principalmente com resistência ao escurecimento, mas possui baixos níveis de produtividade. Assim, ela poderá ser utilizada como genitora em cruzamentos com outras linhagens na geração de genótipos mais produtivos, resistentes à antracnose e com grãos de boa aceitação de mercado.

Em outros dezenove genótipos utilizados como genitores (A 300, A686, Bataav, Carioca Precoce, Chinês II, G916, GNNsel1-27, Iraí, Jalo Itararé, Leg Pintado, Pérola, Quarenteno, Rosa 700, Vac 32, XAN 251, Bolinha Manteiga, Branco Argentino, Jalo Precoce e Carioca Comum) e vinte e cinco linhagens não ocorreu nenhuma marca associada à resistência (Figura 1). Porém, esse não é um dado preocupante, uma vez que não se utilizaram marcadores para todos genes de resistência. Além disso, esses genótipos são utilizados em cruzamentos dirigidos para fornecerem outras características de interesse agronômico, além da resistência à antracnose.

Com esses resultados, foi possível verificar que os marcadores SCARs são eficientes na detecção de genes de resistência em gerações avançadas de feijoeiro. Essa característica pode ser utilizada pelos melhoristas como um fator de seleção de linhagens superiores e passíveis de se tornarem novas cultivares de feijoeiro, desde que seja aliado a outras características de interesse agronômico, tecnológico e nutricional. Esse fato é importante, pois, teoricamente, quanto maior for o número de genes envolvidos na resistência a um determinado patógeno em uma linhagem determinada, mais duradoura e eficiente será a sua resistência visando à prática da piramidação gênica (Kelly et al., 2003).

Através dos marcadores SCARs, também foi possível detectar qual o gene de maior frequência entre os genótipos avaliados. Neste caso, o gene de maior destaque foi o Co-6, proveniente do genótipo AB-136 (marcador SZ20). Em seguida foi o $\mathrm{Co}-4^{2}$, proveniente do genótipo G2333 (marcador SAS13), e o $\mathrm{Co}^{3} 3^{3}$ (marcador SB12), proveniente do genótipo BAT-93 e também da PI-207262 que é um dos genitores do BAT-93 (Kelly e VAlLejo, 2004; Alzate-Marin et al., 2007) (Figuras 2, 3 e 4).

A presença dos genes Co- 6 e Co- $4^{2}$ nestas linhagens deve-se ao grande uso dos genótipos AB-136 e G 2333 no programa de melhoramento do IAC, tanto pelo emprego como doador ou por participação na constituição de linhagens/cultivares já melhoradas.

Alzate-Marin e Sartorato (2004) relataram que cultivares diferenciadoras que possuem o gene $\mathrm{Co}^{-}$ 4 e seus alelos e os genes $\mathrm{Co}_{0} 6$ e $\mathrm{Co}-5$, individualmente ou em associação com outros alelos, são aqueles com maior resistência à antracnose no Brasil. No mesmo trabalho, os autores descreveram que os genótipos Michelite, MDRK, Perry Marrow, Cornell 49-242, Widusa, Kaboon, México 222, PI 207262, TO, TU, AB
136 e G 2333, muito utilizados no programa de melhoramento são resistentes a 7, 31, 26, 29, 27, 35, $9,45,44,49,50$ e 50 raças da antracnose descritas pelos autores no Brasil. Estes resultados comprovam, então, a importância dos genótipos $\mathrm{G} 2333\left(\mathrm{Co}-4^{2}, \mathrm{Co}-\right.$ 5 e $\mathrm{Co}-7)$, PI $207262\left(\mathrm{Co}_{-} 4^{3}\right.$ e $\left.\mathrm{Co}-3^{3}\right)$, TO (Co-4), AB 136 (Co-6 e co-8) e TU (Co-5) como fontes de resistência.

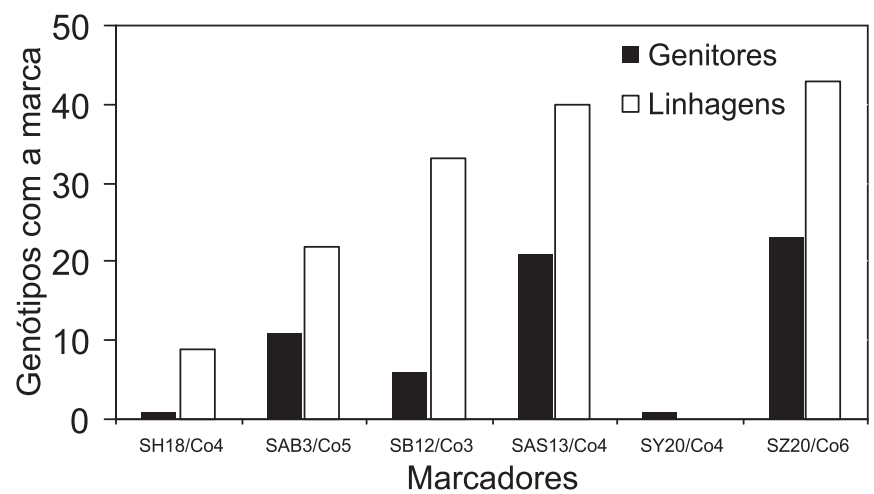

Figura 2. Número de genótipos (genitores e linhagens) de feijoeiro contendo marcas SCARs ligadas a genes de resistência à raça 31 de $C$. lindemuthianum.

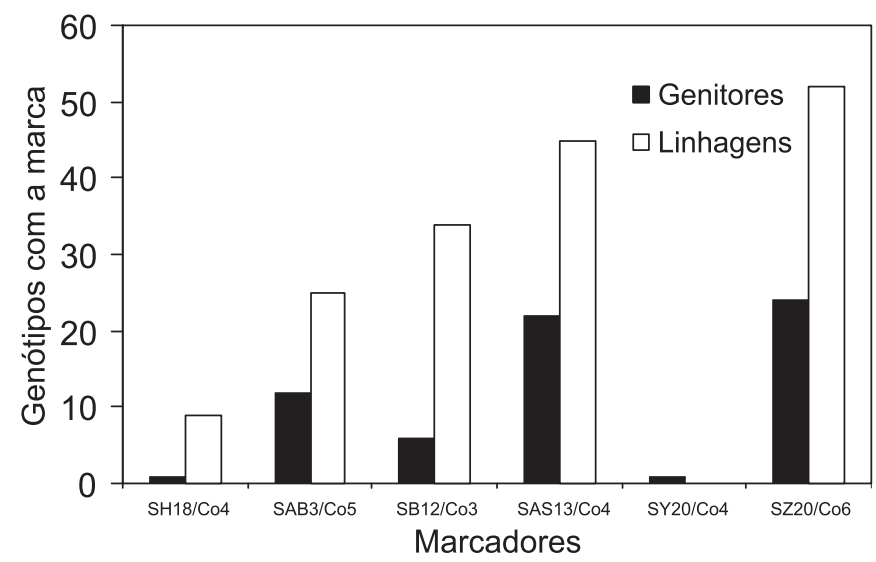

Figura 3. Número de genótipos (genitores e linhagens) de feijoeiro contendo marcas SCARs ligadas a genes de resistência à raça 65 de $C$. lindemuthianum.

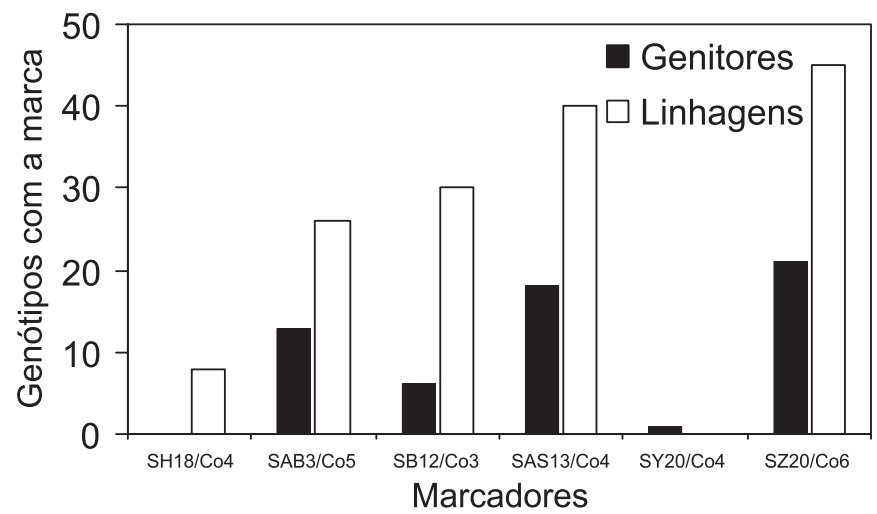

Figura 4. Número de genótipos (genitores e linhagens) de feijoeiro contendo marcas SCARs ligadas a genes de resistência à raça 89 de C. lindemuthianum. 
De acordo com Melotto e Kelly (2000), os genótipos Andinos Kaboon e PI-207262 são importantes fontes doadoras de resistência para raças Andina, pois possuem genes $\mathrm{Co}_{-} 1^{2}$ e $\mathrm{Co}_{0} 3^{3}$, considerados importantes no melhoramento do feijoeiro, por serem incompatíveis com 36 e 9 raças do patógeno da antracnose, respectivamente, sendo também muito utilizados pelo programa do IAC.

No melhoramento de feijoeiro visando à piramidação gênica, uma questão importante que ainda deve ser considerada são as diferenças entre os centros de origem da cultura. A utilização de diferentes genes provenientes dos grupos Andino e Mesoamericano em cruzamentos dirigidos é relatado por BALARDin e KELLy (1998) e também por ChIORATO et al. (2007), os quais demonstraram, nos genótipos de origem Andina, que há maior número de acessos com resistência às três raças avaliadas $(31,65$ e 89$)$ do que os de origem Mesoamericana (30\% contra $15 \%$ respectivamente). Esse número era esperado, uma vez que os isolados utilizados nas avaliações provavelmente pertencem ao conjunto gênico Mesoamericano.

Neste contexto, em trabalhos de piramidação para resistência à antracnose, faz-se necessário a utilização de genótipos Andino como fonte doadora de genes, visando à resistência genética mais duradoura, pois, no Brasil, a maioria das cultivares utilizadas são de origem Mesoamericana. Lembrar também que na piramidação gênica deve-se trabalhar com genes cuja resistência ainda não tenha sido quebrada pelo patógeno, levando-se em consideração a qualidade dos genes envolvidos e não a quantidade (McIntosh e BRown 1997).

O Marcador SY20 (Co-4), por estar exatamente sobre o gene de resistência $(0 \mathrm{cM})$, foi o mais confiável, pois apenas o genótipo G 2338 amplificou a banda associada à resistência esperada (Figuras 2, 3, 4). Esta baixa frequência pode ser explicada pelo fato de o genótipo TO ser pouco utilizado pelo programa de melhoramento do IAC. Este resultado mostra a especificidade desde marcador ao selecionar genótipos contendo o gene Co-4.

A combinação dos resultados das análises moleculares e das respostas das inoculações em campo (Tabela 2) forneceu quatro diferentes respostas: plantas resistentes com presença da marca $(R+)$, plantas resistentes com ausência da marca (R-), plantas suscetíveis com ausência da marca (S-) e, finalmente, plantas suscetíveis com presença da marca $(\mathrm{S}+)$. O fato de em uma planta resistente não ter sido constatado marca associada à resistência (R-) não é relevante, pois esta resistência pode ser causada por genes não avaliados neste trabalho.
O fato de genótipos cujos marcadores moleculares SCARs amplificaram bandas e foram suscetíveis (S+) em análises com a inoculação do patógeno em condições controladas em laboratório, podem ser explicadas, pois em trabalhos com marcadores moleculares o fato de amplificarmos gene de resistência nem sempre se reflete em resistência na planta. Esses problemas muitas vezes podem ocorrer em razão de possíveis deformações no gene, principalmente devido a alguma quebra, ou até mesmo algum crossing-over desigual (SUDUPAK et al., 1993; Melotto et al., 2004).

Nesse contexto, possíveis mudanças nessa região podem fazer com o que o gene não confira mais resistência ao patógeno. Apesar desse gene não ser mais efetivo, poderá ser amplificado em análises moleculares, pois muitas vezes os marcadores estão situados próximos ao gene e não sobre ele, e interpretações erradas poderão ocorrer em relação às linhagens que amplificaram o marcador ligado ao gene de resistência, mas são suscetíveis fenotipicamente. Assim, inoculações com o patógeno permitem corrigir esses problemas, como forma de confirmar a possível resistência ou suscetibilidade do genótipo frente ao patógeno.

Considerando esses resultados, confirma-se a facilidade da utilização dos marcadores SCARs na seleção de genótipos contendo genes piramidados para indicação de linhagens avançadas, candidatas a se tornarem cultivares e na identificação de genes de resistência mais freqüentes na população. Porém, para utilização dos SCARs na seleção de genitores resistentes, com base nos resultados apresentados na tabela 2 , sugere-se que as inoculações com patógeno devem ser realizadas para confirmar a resistência destes genitores antes do processo de seleção das progênies obtidas com a utilização dos marcadores moleculares.

\section{CONCLUSÕES}

1 - Os marcadores moleculares SCARs identificaram os genes de resistência presentes nos 118 genótipos avaliados, auxiliando o melhorista na seleção de linhagens contendo o maior número de genes reunidos em um mesmo genótipo. Entre eles, estão os genótipos G 2338, Pompadour, Vax 1 e as linhagens Gen96A5-P1-1, Gen99TG35-29, Gen99TG47-38-2, Gen96A98-12-1-51-1, Gen96A3-P41-1, Gen96A100-6-1-53-1, Gen99TG36-9, Gen96A14-7-3-15-3V-2 e Gen99TG50-47 que possuem ao menos quatro genes de resistência incorporados em um mesmo genótipo. 
2 - Também permitiu identificar os genitores com genes de resistência específicos, possibilitando a utilização no programa de melhoramento, em cruzamentos dirigidos, visando à incorporação da resistência em determinado genótipo ou progênie (piramidação gênica). Em populações, os SCARs podem identificar os genes mais frequentes na população. Neste caso, os genes de maior destaque foram o $\mathrm{Co}-6$ e $\mathrm{Co}_{0} 4^{2}$, seguidos por $\mathrm{Co}_{-} 3^{3}$, Co- 5 e $\mathrm{Co}-4$.

\section{REFERÊNCIAS}

ALZATE-MARIN, A.L.; MENARIN, H.; CARVALHO, G.A.; PAULA, J.J.; BARROS, E.G.; MOREIRA, M.A. Improved selection with newly identified RAPD markers linked to resistance gene to four pathotypes of Colletotrichum lindemuthianum in common bean. Phytopathology, v.89, n.4, p. 281-285, 1999.

ALZATE-MARIN, A.L.; MENARIM, H.; CHAGAS, J.M.; BARROS, E.G.; MOREIRA, M.A. Identification of RAPD marker linked to the Co-6 anthracnose resistant gene in common bean cultivar AB 136. Genetics and Molecular Biology, v. 23 n. 3, p. 633-637, 2000.

ALZATE-MARIN, A.L.; MENARIM, H.; BAÍA, G.S.; PAULA Jr, T.J.; de SOUZA, K.A.; da COSTA, M.R.; de BARROS, E.G.; MOREIRA, M.A. Inheritance of a anthracnose resistance in the common bean differential cultivar G 2333 and identification of a new molecular marker linked to the $\mathrm{Co}-4^{2}$ gene. Journal of Phytopathology, Berlin, v. 149, p. 259-264, 2001.

ALZATE-MARIN, A.L.; SILVA, M.M.G.; MOREIRA, M.A.; BARROS, E.G. Validation of RAPD markers linked to Co-4 anthracnose resistance alleles in common bean cultivar PI 207. 262. Annual Report of the Bean Improvement Cooperative, Michigan, v. 45, p. 114-115, 2002.

ALZATE-MARIN, A.L.; SARTORATO, A. Analysis of the pathogenic variability of Colletotrichum lindemuthianum in Brazil. In: Annual Report of the Bean Improvement Cooperative, Michigan, v. 47, p. 241-242, 2004.

ALZATE-MARIN, AL.; SOUZA, K.A.; SILVA, M.G.M.; OLIVEIRA, E.J.; MOREIRA, M.A.; BARROS, E.G. Genetic characterization of anthracnose resistance genes $\mathrm{Co}^{-} 4^{3}$ and Co9 in common bean cultivar Tlalnepantla 64 (PI 207262), Euphytica, Netherlands, v. 154, p. 1-8, 2007.

ARRUDA, M.C.C.; ALZATE-MARIN, A.L.; CHAGAS, J.M.; MOREIRA, M.A.; BARROS, E.G. Identification of Random Amplified Polymorphic DNA markers linked to the Co-4 resistance gene to Colletotrichum lindemuthianum in common bean. Phytopathology, v. 90, n. 7, p. 758-761. 2000.

ARRUDA, K.M.A.; MELO, C.L.P.; SOUZA, T.L.P.O.; CARNEIRO, J.E.S.; MOUREIRA, M.A.; BARROS, E.G. Caracterização fenotípica de linhagens de feijão tipo "carioca" quanto à resistência a patógenos. In: CONAFE, Goiânia, p. 153-157, 2005.
AWALE, H. E.; KELLY, J.D. Development of SCAR markers linked to $\mathrm{Co}-4^{2}$ gene in common bean. In: Annual Report of the Bean Improvement Cooperative, Michigan,v. 44, p. 119120, 2001.

BALARDIN, R.S.; JAROSZ, A.M.; KELLY, J.D. Virulence and molecular diversity in Colletotrichum lindemuthianum from South, Central and North America. Phytopathology, Netherlands, v.87, p.1184-1191, 1997.

BALARDIN, R.S.; KELLY, J.D. Interaction between Colletotrichum lindemuthianum races and gene pool diversity in Phaseolus vulgaris. Journal of the American Society for Horticultural Science, Alexandria, v.123, n.6, p.1038-1047, 1998.

BEAN IMPROVEMENT COOPERATIVE. Disponível em: http:/ / www.css.msu.edu/bic/. Acesso em junho de 2008.

CARBONELL, S.M.; ITO, M.F.; POMPEU, A.S.; FRANCISCO, F.; RAVAGNANI, S.; ALMEIDA, A.L.L. Raças fisiológicas de Colletotrichum lindemuthianum e reação de cultivares e linhagens de feijoeiro no Estado de São Paulo. Fitopatologia Brasileira, Brasília, v. 24, n.1, p. 60-65, 1999.

CASTANHEIRA, A.L.M.; SANTOS, J.B. dos.; FERREIRA, D.F.; MELO, L.C. Identification on common bean alleles resistant to anthracnose using RAPD. Genetics and Molecular Biology, Ribeirão Preto, v. 22, n. 4, p. 565-569, 1999.

CHIORATO, A.F.; CARBONELL, S.A.M.; BENCHIMOL, L.L.; CHIAVEGATO, M.B.; DIAS, L.A.S.; COLOMBO, C.A. Genetic diversity in common bean accessions evaluated by means of morpho-agronomical and RAPD data. Scientia Agrícola, Piracicaba, v.64, n.3, p. 256-262, 2007.

CIAT (Centro Internacional de Agricultura Tropical). Research constraints provisionally identified by CIAT. In: WORKSHOP ON ADVACED PHASEOLUS BEAN RESEARCH NETWORK, 1990, Cali, Colômbia. p.30. (Impresso)

FIGUEIREDO, M. B. Aplicação do método Castellani para conservação de fungos patogênicos em plantas. Biológico, São Paulo, v. 33, p. 9-13. 1967.

GEFFRROY, V.; SÉVIGNAC, M.; De OLIVEIRA, J.; FOUILLOUX, G.; SKROCH, P.; THOQUET, P.; GEPTS, P.; LNGIN, T.; DRON, M. Identification of an ancestral resistance gene cluster involved in the co-evolution process between Phaseolus vulgaris and its fungal pathogen Colletotrichum lindemuthianum. Molecular Plant-Microbe Interactions, v. 12, p. 774-782, 1999.

HITTALMANI, S.; PARCO, A.; MEW, T.V.; ZEIGLER, R.S.; HUANG, N. Fine mapping and DNA marker-assisted pyramiding of the three major genes for blast resistance in rice. Theoretical and Applied Genetics, Berlin, v.100, p. 1121$1128,2000$.

HOISINGTON D, KHAIRALLAH M, GONZÁLEZ-DE-LEÓN D. Laboratory Protocols. Applied Molecular Genetics Laboratory. 2.ed. México, DF: CIMMYT, 1994. 
HUANG, N.; ANGELES, E.R.; DOMINGO, J.; MAGPANTAY, G.;SINGH, S.;ZHANG, G.; KUMARAVADIVEL, N.; BENNETT, J.; KHUSH, G.S. Pyramiding of bacterial blight resistance genes in rice: marker-assisted selection using RFLP and PCR. Theoretical and Applied Genetics, Berlin, v. 95, n. 3, p. 313320, 1997.

KELLY, J.D.; GEPTS. P.; MIKLAS, P.N.; COYNE, D.P. Tagging and mapping of genes and QTL and molecular marker-assisted selection for traits of economic importance in bean and cowpea. Field Crops Research, Orlando, v.82, p.135-154, 2003.

KELLY, J.D.; VALLEJO, A. V. A comprehensive review of the major genes conditions resistance to anthracnose in common bean. HortScience, Alexandria, v, 39, n. 6, p. 1196-1207, 2004.

MAHUKU, S.G.; RIASCOS, J.J. Virulence and molecular diversity within Colletotrichum lindemuthianum isolates from Andean and Mesoamerican bean varieties and regions. European Journal of Plant Pathology, Netherlands, v.110, p.253-263, 2004.

McINTOSH, R.A.; BROWN, G.N. Anticipatory breeding for resistance to rust diseases in wheat. Annual Review of Phytopathology, Palo Alto, v. 35, p. 311-326, 1997.

MELOTTO, M.; KELLY, J.D. SCAR marker linked to major disease resistance genes in common bean. Annual Report of the Bean Improvement Cooperative, Michigan, v. 41, p. 64-65, 1998.

MELOTTO, M.; KELLY, J.D. An allelic series at the Co-1 gene conditioning resistance to anthracnose in common bean of Andean origin. Euphytica, Dordrecht, v, 116, p. 143-149, 2000.

MELOTTO, M.; COELHO, M.F.; PEDROSA-HARAND, A.; KELLY, J.D.; CAMARGO, L.E.A. The anthracnose resistance locus $\mathrm{Co}-4$ of common bean is located on chromosome 3 and contains putative disease resistance-related genes. Theoretical and Applied Genetics, Berlin, v. 109, n. 4, p. 690-699, 2004.

MÉNDEZ DE VIGO, B.; RODRÍGUEZ. C.; PAÑEDA. A.; GIRALDEZ. R.; FERREIRA. J.J. Development of a SCAR marker linked to Co-9 in common bean. Annual Report of the Bean Improvement Cooperative, Michigan, v. 45, p. 116-117, 2002.

NIETSCHE, S.; BORÉM, A; CARVALHO, G.A.; OCHA, R.C.; PAULA, Jr, T.J.; BARROS de, E.G.; MOREIRA, M.A. RAPD and SCAR markers linked to gene conferring resistance to Angular Leaf Spot in Common Bean. Journal Phytopathology, Berlin, v. 148, p.117-121, 2000.

QUEIROZ, V.T.; SOUSA, C.S.; COSTA, M.R.;SANGLAD, D.A.; ARRUDA, K.M.A.; SOUZA, T.L.P.O.; RAGAGNIN, V.A.; BARROS, E.G.; MOREIRA, M.A. Development of SCAR markers linked to common bean anthracnose resistance genes Co-4 and Co-6. In: Annual Report of the Bean Improvement Cooperative, Michigan, v.47, p. 249-250, 2004.

RAGAGNIN, V.A.; ALZATE-MARIN, A.L.; SOUZA, T.L.P.O.; ARRUDA, K.M.A.; MOREIRA, M.A.; BARROS, E.G. Avaliação de isolinhas de feijoeiro a diferentes patótipos de Colletotrichum lindemuthianum, Uromyces appendiculatus e Phaeoisariopsis griseola. Fitopatologia Brasileira, Brasília, v. 28, p. 591-596, 2003.
RAVA, C.A.; PURCHIO, A.F. \& SARTORATO, A. Caracterização de patótipos de Colletotrichum lindendemuthianum que ocorreram em algumas regiões produtoras de feijoeiro comum. Fitopatologia Brasileira, Brasília, v. 19, p.167-173, 1994.

SANCHEZ, A.C.; BRAR, D.S.; HUANG, N.; Z. LI, N.; KHUSH, G.S. Sequence Tagged Site Marker-Assisted Selection for Three Bacterial Blight Resistance Genes in Rice. Crop Science, Madison, v.40, p. 797-803, 2000.

SINGH, S.; SIDHU, J.S.; HUANG, N.; VIKAL, Y.; LI, Z.; BRAR, D.S.; DHALIWAL, H.S.; KHUSH, G.S. Pyramiding three bacterial blight resistance genes (xa5, xa13 and Xa21) using marker-assisted selection into indica rice cultivar PR106. Theoretical and Applied Genetics, Berlin, v.102, n.6-7, p. 10111015, 2001.

SUDUPAK, M.A.; BENNETZEN, J.L.; HULBERT, S.H. Unequal exchange and meiotic instability of disease-resistance genes in the $R p 1$ region of maize. Genetics, Pittsburgh, v. 133, p. 199-125, 1993.

TALAMINI, V.; SOUZA, E.A.; POZZA, E.A.; CARRIJO, F.R.F.; ISHIKAWA, F.H.; SILVA, K.J.D.; OLIVEIRA, F.A. Identificação de raças patogênicas de Colletotrichum lindemuthianum a partir de isolados provenientes de regiões produtoras de feijoeiro comum. Summa Phytophatológica, Botucatu, v. 30, p. 371$375,2004$.

THOMAZELLA, C.; GONÇALVES-VIDIGAL, M. C.; VIDA, J. B.; VIDIGAL FILHO, P. S.; RIMOLDI, F. Identification of Colletotrichum lindemuthianum races in Phaseolus vulgaris L. Annual Report of the Bean Improvement Cooperative, Michigan, v. 43, p. 82-83, 2000.

VALLEJO, V.; KELLY, J.D. Development of a SCAR marker linked to the Co-5 locus in common bean. Annual Report of the Bean Improvement Cooperative, Michigan, v. 44, p. 121$122,2001$.

YOUNG, R.; MELOTO, M.; NODARI, R.O.; KELLY, J.D. Markerassisted dissection of the oligogenic anthracnose resistance in the common bean cultivar, 'G2333'. Theoretical and Applied Genetics, Berlin, v. 96, p. 87-94, 1998. 